\title{
Políticas Públicas de Democracia Digital no Governo Federal: INDIVIDUALIZAÇÃO DA CIDADANIA?
}

\author{
Daniel Pitangueira de Avelino² \\ Igor Ferraz da Fonseca ${ }^{3}$ \\ João Cláudio Basso Pompeu ${ }^{4}$
}

\section{INTRODUÇÃO}

Este artigo tem como objetivo, por meio de pesquisa exploratória, iniciar um mapeamento preliminar das principais iniciativas relacionadas ao tema da democracia digital ativas no governo federal no ano de 2019, com ênfase nos processos de individualização da participação dos cidadãos. ${ }^{5}$

A partir de uma leitura teórica e conceitual, realizou-se um levantamento (qualitativo e não exaustivo) em torno das principais políticas públicas em funcionamento na administração pública federal relacionadas aos temas de democracia digital. Foram identificados três órgáos que, na opiniáo dos nossos interlocutores, ${ }^{6}$ apresentavam as experiências mais relevantes na área: a Secretaria de Governo Digital (SGD) do Ministério da Economia (ME); a Coordenação-Geral de Governo Aberto e Transparência (CGAT) e a Ouvidoria-Geral da União (OGU), ambas da Controladoria-Geral da Uniâo (CGU).

Em tal recorte, foram realizadas entrevistas com gestores dos órgãos acima elencados, apresentadas nas seçóes a seguir, com o objetivo de retratar o estado da arte (atuaçáo e principais iniciativas) das políticas públicas sob sua responsabilidade. As consideraçóes finais apontam que as principais iniciativas de democracia digital identificadas na pesquisa partilham o foco na individualização da cidadania, em que o cidadão é prioritariamente tratado como usuário de serviços públicos.

\section{INDIVIDUALIZAÇÃO DA CIDADANIA E DEMOCRACIA DIGITAL}

$\mathrm{O}$ individualismo é considerado pelas ciências sociais como uma característica intrínseca das sociedades contemporâneas, muito embora haja divergências em relação às suas consequências políticas. Para Giddens (1999, p. 47), o individualismo institucional não é incompatível com a solidariedade social, mas típico de uma "época de transição moral". Por sua vez, Bauman (2005) vê a individualização de forma menos otimista e alerta, entre outros efeitos, contra a apatia política, que pode resultar da "destruição dos alicerces do poder de Estado" (Bauman, 2005, p. 68). Essas contradiçôes compóem o paradoxo apontado por Beck e Beck-Gernsheim (2001), em que o aumento do envolvimento político no nível microcósmico pode estar erodindo as condiçôes estruturais para consensos políticos.

1. DOI: http://dx.doi.org/10.38116/bapi25art4

2. Especialista em políticas públicas e gestão governamental na Diretoria de Estudos e Políticas do Estado, das Instituições e da Democracia (Diest) do Ipea. E-mail: <daniel.avelino@ipea.gov.br>.

3. Técnico de planejamento e pesquisa na Diest/lpea.E-mail: <igor.fonseca@ipea.gov.br>.

4. Especialista em políticas públicas e gestão governamental na Diest/lpea.E-mail: <joao.pompeu@ipea.gov.br>.

5. Este artigo foi baseado em Avelino, Pompeu e Fonseca (no prelo). A discussão teórica mais ampla e outras informações metodológicas podem ser acessadas nesse documento.

6. O levantamento preliminar foi feito por meio de contatos telefônicos e pessoais com gestores de áreas do governo federal relacionadas aos temas de democracia digital. 
O ponto comum das diversas análises é a valorização da influência das novas ferramentas de comunicaçáo. Castells (2013), ponderando que o processo de comunicaçáo entre experiências individuais exige "a consonância cognitiva entre emissores e receptores da mensagem e um canal de comunicação eficaz", considera as redes digitais como os veículos com maior potencial de amplificação da história humana, o que o leva a afirmar que "os movimentos sociais em rede da era digital representam uma nova espécie em seu gênero" (Castells, 2013, p. 23-24). Para explicar as formas individualizadas de atuação política, alguns conceitos novos foram propostos, como a "ação coletiva individualizada" (Micheletti, 2003) ou a "ação conectiva” (Bennet e Segerberg, 2012).

Assim, com precedentes no interacionismo simbólico e na teoria da ação comunicativa, Gohn (2019) argumenta que é incorporada nas teorias da participação social a abordagem relacional, diante de um "mundo onde, em princípio, todos podem participar e todas as formas políticas e culturais de expressão têm espaço, das mais progressistas às mais conservadoras e repressoras" (Gohn, 2019, p. 74).

Nesta confluência emerge como área de estudos a democracia digital, definida por Gomes (2018, p. 14) como "a concepçáo segundo a qual recursos tecnológicos, projetos baseados em tecnologias da comunicação e até as experiências de uso pessoal e social das tecnologias de comunicação e informação podem ser empregados para produzir mais democracia e melhores democracias".

Os estudos sobre democracia digital se dividem em vários temas. ${ }^{7}$ Nesta pesquisa, optamos por enfatizar as áreas de governo eletrônico, transparência e dados abertos, pois elas estão em contínuo crescimento e profissionalização no âmbito do governo federal há pelo menos duas décadas (Zuccolotto, Teixeira e Riccio, 2015) e são a base das três experiências aqui apresentadas.

Para além dos temas de e-transparência, ganha força no século XXI, na agenda de governo eletrônico, a ideia de e-public service delivery, ou seja, a visão que enfatiza a responsabilidade estatal no fornecimento de serviços públicos on-line para os cidadãos (Gomes, 2018). Há quase duas décadas, já se apontava que o efeito das tecnologias de informação e comunicação para a entrega de serviços eletrônicos aos cidadãos era eminentemente positivo (Porebski, 2002).

O momento atual é propício ao aprofundamento desses temas. Do ponto de vista da relação entre Estado e sociedade, é possível observar no Brasil o fortalecimento de um novo modelo de participação social. O governo federal estimula a interaçáo entre o Estado e os cidadãos, considerados em sua forma individual (e, por vezes, atomizada), em que a internet aparece como canal preferencial de interlocução de forma direta, sem a necessidade de mediação por organizações da sociedade civil ou outras instâncias de participação social. Observa-se a vinculação cada vez maior do conceito de cidadania e das formas de interação entre Estado e sociedade a partir do paradigma no qual o cidadáo é, prioritariamente, identificado como usuário. No formato digital, a oferta de dados e serviços públicos passa a ser o objeto prioritário do diálogo, o qual vai funcionar também como uma fonte de informaçóes para a gestão pública.

O conceito individualizado de cidadania pode representar uma tendência no governo federal, considerando a retração recente (Avelino, Alencar e Costa, 2017; Avelino, Fonseca e Pompeu, 2020) de instituições participativas, em que as formas de participação eram marcadamente coletivas e onde organizaçóes da sociedade civil atuavam a partir do conceito de representação ampliada (Almeida,

7. Para uma análise didática dos diversos temas e áreas em torno da democracia digital, ver Gomes (2018). 
2013; Avritzer, 2007; Lavalle, Houtzager e Castello, 2006a; 2006b; Lüchmann, 2007). É nessa linha que se apresentarão as três experiências de democracia digital descritas nas seçóes a seguir.

\section{$3 S G D$}

A SGD é um órgão vinculado à Secretaria Especial de Desburocratização, Gestão e Governo Digital, do Ministério da Economia. Tem como foco de atuação o conceito de serviço público e, ao mesmo tempo, o aperfeiçoamento dos processos internos de governo, com uso intensivo de dados sobre qualidade dos serviços e grau de confiança dos cidadãos. Nesse sentido, utiliza diversas bases de dados, como o Latinobarómetro ${ }^{8}$ e o Censo de Serviços Públicos, realizado pela Escola Nacional de Administração Pública (ENAP) desde 2018.

Segundo o Decreto no 8.936/2016, a SGD coordena a migração dos serviços oferecidos pelo governo federal para a Plataforma de Cidadania Digital. Com a publicação do Decreto n⿳o 9.756/2019, o domínio <servicos.gov.br>, previsto no decreto anterior, está sendo substituído pelo portal único <gov.br>, que deve suplantar os domínios atuais até 2020. O diálogo com os demais órgãos federais resulta na apresentação de um plano de transformaçáo digital, previsto no Decreto no 9.319/2018, elaborado com o apoio da SGD, contendo compromissos setoriais para a implantação da Estratégia Brasileira para a Transformação Digital. Além disso, a SGD também atua propondo medidas de simplificação de acesso e proteção de dados pessoais, entre outras.

Em suma, está em curso um processo intensivo de migraçáo de serviços públicos para a via digital, que envolve não apenas a mudança na forma de oferta. Há também uma estratégia ativa de simplificação e ampliação do acesso, com foco no usuário, chamado a participar do processo por meio de ferramentas digitais, como o Simplifique!. ${ }^{9}$ Nesse canal, o cidadão opina sobre a forma de oferta do serviço e oferece sugestóes de simplificação, sempre de forma individualizada e tendo o órgão público como interlocutor.

\section{OUVIDORIA-GERAL DA UNIÃO}

A OGU é um órgão vinculado à CGU e, atualmente, sua agenda de atuação está fundamentada na defesa dos direitos dos usuários de serviços públicos, na melhoria da sua qualidade (segundo os critérios de eficiência, simplificação e desburocratização) e no combate à corrupção.

Uma ferramenta importante para a atuação da OGU é o Sistema Informatizado de Ouvidorias do Poder Executivo Federal (e-Ouv), criado em 2015 e adotado por toda a administração pública federal, conforme Decreto no ${ }^{-9.492 / 2018}$. Nele, as manifestaçóes são inseridas de forma padronizada e, como resultados, além do retorno ao usuário, são produzidos dados agregados, disponíveis publicamente por meio do painel Resolveu? ${ }^{10} \mathrm{O}$ acesso público ocorre pela interface Fala.BR Plataforma Integrada de Ouvidoria e Acesso à Informação. ${ }^{11}$ Há a possibilidade de desenvolvimento de "aplicativos cívicos" por terceiros, por meio do procedimento Me-Ouv. ${ }^{12}$

A agenda de trabalho da OGU inclui outras ações, como a implementação dos conselhos de usuários de serviços públicos, iniciativa inspirada em experiências de participaçáo comunitária, como

8. Disponível em: <http://www.latinobarometro.org/lat.jsp>.

9. Disponível em: <http://www.simplifique.gov.br/>.

10. Disponivel em: <http://paineis.cgu.gov.br/resolveu/index.htm>.

11. Disponível em: <https://sistema.ouvidorias.gov.br/publico/Manifestacao/SelecionarTipoManifestacao.aspx?ReturnUrl=\%2f>.

12. Disponível em: $<$ http://pesquisa.in.gov.br/imprensa/jsp/visualiza/index.jsp?data=08/11/2017\&jornal=515\&pagina=104\&totalArquivos=168> . 
o Decide Madrid ${ }^{13}$ e o Decidim Barcelona, ${ }^{14}$ na Espanha. Há ainda iniciativas presenciais, como o monitoramento ativo da qualidade de serviços públicos (Monitorando), no âmbito do Programa de Avaliação Cidadã de Serviços e Políticas Públicas (PROCID). ${ }^{15}$

Em suma, a OGU vê como foco do seu trabalho a coleta, análise e difusão de informaçóes. O cidadáo participa de todas as suas açóes, predominantemente de forma individualizada, como demandante, mas também, em alguns casos, de forma coletiva (conselhos de usuários), presencial (monitoramento ativo) ou mesmo colaborativa (Me-Ouv).

\section{CGAT}

A CGAT é parte integrante da Diretoria de Transparência e Controle Social, que por sua vez integra a estrutura da Secretaria de Transparência e Prevenção da Corrupção, da Controladoria-Geral da União. Seu produto mais conhecido é o Portal da Transparência do governo federal, site que tem o objetivo de garantir e ampliar a transparência da gestão pública e fortalecer a participação social na fiscalização dos gastos e investimentos do Poder Executivo Federal. ${ }^{16}$ De modo mais amplo, a CGAT é responsável pela gestão e acompanhamento da Política de Dados Abertos do Executivo Federal ${ }^{17}$ e com a implementaçáo da Lei de Acesso à Informação (LAI). ${ }^{18}$

Além desses painéis e portais, outras iniciativas também são desenvolvidas pela CGU no tema de transparência e dados abertos. Aqui, destaca-se a Escala Brasil Transparente (EBT), ${ }^{19}$ que consiste em uma metodologia para medir a transparência pública em estados e municípios brasileiros e avalia o grau de cumprimento de dispositivos da LAI. Vale ressaltar que a CGAT é responsável pelo acompanhamento da presença do Brasil na Open Government Partnership, e cabe à CGU o acompanhamento da evolução da implementação dos compromissos que o Brasil assumiu nessa parceria.

Em suma, a CGAT é a principal unidade do governo federal responsável por pensar de forma estratégica a ampliação da transparência pública. Os cidadãos interagem com o órgão, de forma individualizada, como demandantes de informação (via LAI) ou com sugestóes de ampliação da transparência, tendo o órgão público como interlocutor.

\section{CONSIDERAÇÕES FINAIS}

Apesar de se tratar de um esforço ainda preliminar, já é possível tirar algumas conclusôes desta pesquisa, que ainda está em andamento no Ipea. A partir desse mapeamento, foi observado que a CGU tem papel central e orientador em torno das políticas de governo aberto e de ouvidorias no âmbito federal. Outra frente identificada na pesquisa foi a emergência e, sobretudo, o fortalecimento da agenda da digitalização de serviços públicos, assumida pela Secretaria de Governo Digital do Ministério da Economia. As situaçóes analisadas confirmam o fortalecimento de uma perspectiva individual na interação entre Estado e cidadãos, em que esses últimos dialogam com os órgãos

13. Disponivel em: $<$ https://decide.madrid.es/>.

14. Disponível em: <https://www.decidim.barcelona/>.

15. Disponível em: <https://www.ouvidorias.gov.br/ouvidorias/legislacao/portarias/portaria-1864-de-2016-procid.pdf>.

16. Estatísticas de acesso disponíveis em: <http://www.portaltransparencia.gov.br/estatisticas?ordenarPor=mesAno\&direcao=desc $>$.

17. As estatísticas com o resultado desse trabalho podem ser acompanhadas no Painel Monitoramento de Dados Abertos, disponível em: $<$ http://paineis.cgu.gov.br/dadosabertos/index.htm>.

18. Dados sobre implementação da LAl estão no Painel Lei de Acesso à Informação, disponível em: <http://paineis.cgu.gov.br/lai/index.htm>.

19. Disponível em: <http://www.cgu.gov.br/assuntos/transparencia-publica/escala-brasil-transparente>. 
públicos de forma isolada, sem a previsão de momentos de deliberação ou interaçáo coletiva, tal como ocorre em instituiçóes participativas como conselhos e conferências.

O caso da Ouvidoria se revela como o grande achado da pesquisa. Não apenas é uma experiência já longeva, contemporânea de outros paradigmas de participação social, como também articula atualmente canais presenciais com digitais, interaçóes individuais com coletivas. Pode ser um caso interessante de hibridismo para aprofundamento em estudos futuros.

É importante ressaltar que esta pesquisa apresentou duas limitaçôes relevantes. A primeira é o seu caráter inicial e exploratório, que não se presta a análises mais aprofundadas sobre os casos escolhidos. A segunda é a sua abrangência, restrita a três situaçóes identificadas como relevantes, mas que poderiam ser comparadas a outras menos conhecidas, para formar um retrato mais completo das políticas relacionadas ao tema. Contudo, isso náo diminui a importância do trabalho de mapeamento, que poderá ser desenvolvido em uma futura agenda de pesquisas.

Mover o foco a interaçóes mediadas pelas vias digitais, como aquelas descritas neste artigo, com ênfase nos indivíduos, é uma alternativa para compreender os processos contemporâneos de participação política no Brasil.

\section{REFERÊNCIAS}

ALMEIDA, D. R. A relação contingente entre representação e legitimidade democrática sob a perspectiva da sociedade civil. Revista Brasileira de Ciências Sociais, n. 28, p. 45-66, 2013.

AVELINO, D; ALENCAR, J; COSTA, P. Colegiados nacionais de políticas públicas em contexto de mudanças: equipes de apoio e estratégias de sobrevivência. Rio de Janeiro: Ipea, 2017. (Texto para Discussão, n. 2340).

AVELINO, D.; FONSECA, I; POMPEU, J. Conselhos nacionais de direitos humanos: uma análise da agenda política. Brasília: Ipea, 2020.

AVELINO, D; POMPEU, J.; FONSECA, I. Democracia digital: mapeamento de experiências em dados abertos, governo digital e ouvidorias públicas. Brasília: Ipea, no prelo.

AVRITZER, L. Sociedade civil, instituições participativas e representação: da autorização à legitimidade da ação. Dados, n. 50, p. 443-464, 2007.

BAUMAN, Z. Vidas desperdiçadas. Rio de Janeiro: Jorge Zahar, 2005.

BECK, U.; BECK-GERNSHEIM, E. Individualization: institutionalized individualism and its social and political consequences. London: Sage Publications, 2001.

BENNETT, W. L.; SEGERBERG, A. The logic of connective action: Digital media and the personalization of contentious politics. Information, Communication \& Society, n. 15, p. 739-768, 2013.

CASTELLS, M. Redes de indignaçáo e esperança: movimentos sociais na era da internet. Rio de Janeiro: Zahar, 2013. 
GIDDENS, A. Estruturalismo, pós-estruturalismo e a produção da cultura. In: GIDDENS, A.; TURNER, J. (Org.). Teoria social hoje. São Paulo: UNESP, 1999.

GOHN, M. da G. Teorias sobre a participaçáo social: desafios para a compreensão das desigualdades sociais. Cad. CRH, Salvador, v. 32, n. 85, p. 63-81, abr. 2019.

GOMES, W. A democracia no mundo digital: história, problemas e temas. São Paulo: Edições Sesc, 2018.

LAVALLE, A. G.; HOUTZAGER, P. P.; CASTELLO, G. Representação política e organizações civis: novas instâncias de mediação e os desafios da legitimidade. Revista Brasileira de Ciências Sociais, n. 21, p. 43-66, 2006 a.

Democracia, pluralização da representação e sociedade civil. Lua Nova, n. 67, p. 49-103, 2006 b.

LÜCHMANN, L. H. A representação no interior das experiências de participação. Lua Nova, n. 70, p. 139-170, 2007.

MICHELETTI, M. Shopping with and for virtues. In: MICHELETTI, M. (Ed.). Political virtue and shopping. New York: Palgrave Macmillan, 2003. p. 149-168.

POREBSKI, L. Three faces of electronic democracy. European Conference on Information Systems - ECIS. Gdansk: Polônia, 2002.

ZUCCOLOTTO, R.; TEIXEIRA, M. A.; RICCIO, E. L. Transparência: reposicionando o debate. Revista Contemporânea de Contabilidade, v. 12, n. 25, p. 137-158, 2015. 